\title{
Anabases
}

ANABASES Traditions et réceptions de l'Antiquité

$14 \mid 2011$

Varia

\section{Françoise WAQUET, Respublica academica. Rituels universitaires et genres du savoir (XVII ${ }^{e}$ XXI ${ }^{e}$ siècles)}

\author{
Catherine Valenti
}

\section{OpenEdition}

Journals

Édition électronique

URL : http://journals.openedition.org/anabases/2844

DOI : 10.4000/anabases. 2844

ISSN : 2256-9421

Éditeur

E.R.A.S.M.E.

Édition imprimée

Date de publication : 1 octobre 2011

Pagination : 290-291

ISSN : 1774-4296

\section{Référence électronique}

Catherine Valenti, «Françoise WAQUET, Respublica academica. Rituels universitaires et genres du savoir (xVII ${ }^{e}-\left.x x\right|^{e}$ siècles) », Anabases [En ligne], 14 | 2011, mis en ligne le 01 octobre 2011, consulté le 21 septembre 2020. URL : http://journals.openedition.org/anabases/2844 ; DOI : https://doi.org/ 10.4000/anabases.2844

Ce document a été généré automatiquement le 21 septembre 2020.

(c) Anabases 


\title{
Françoise WAQUET, Respublica academica. Rituels universitaires et genres du savoir (XVII ${ }^{e}-\mathrm{XXI}^{e}$ siècles)
}

\author{
Catherine Valenti
}

\section{RÉFÉRENCE}

Françoise WAQUET, Respublica academica. Rituels universitaires et genres du savoir (XVII ${ }^{e}$-XXI ${ }^{e}$ siècles), Paris, PUPS, 2010, $251 \mathrm{p}$.

20 euros / ISBN 978-2-84050-710-9.

1 Avec Respublica academica, Françoise Waquet prolonge et approfondit la réflexion entamée en 2008 dans Les enfants de Socrate. Généalogie intellectuelle et transmission du savoir. S'intéressant toujours à la "République des lettres ", envisagée sur la même période chronologique - $\mathrm{du} \mathrm{xVII}^{\mathrm{e}}$ siècle au début $\mathrm{du} \mathrm{xxI}^{\mathrm{e}}-$, elle étudie spécifiquement cette fois les rituels et genres universitaires, partant du principe que l'Université est une société ritualisée et que le savoir, qui est son objet, est informé par des genres obéissant à des règles bien précises que l'auteur se propose d'analyser ici.

Composé principalement d'articles - pour la plupart remaniés - parus entre 1983 et 2008 , le recueil propose également deux contributions inédites, l'une sur l'histoire de la lettre de recommandation, l'autre sur la session poster. Plus qu'une simple juxtaposition d'articles toutefois, l'ouvrage de Françoise Waquet s'articule autour d'un fil directeur particulièrement pertinent : celui de la communication du savoir, avec ses pratiques et ses idéaux, ses modes et ses formes, ses obstacles et ses flux. Le volume envisage en effet rituels et genres universitaires comme des éléments du partage des connaissances. Le savoir universitaire se construit de manière collective, et il se donne bien plus qu'il ne se monnaye: le don en effet a toute sa place dans l'économie du savoir, comme Françoise Waquet l'avait déjà montré dans Les enfants de Socrate où elle 
réfléchissait notamment sur les modalités et la « gratuité » de la transmission du savoir du maître à ses disciples.

3 Les chapitres sont regroupés en deux parties. La première, intitulée "Rites, codes, usages ", analyse un certain nombre de pratiques universitaires ritualisées, depuis l'échange de portraits entre savants aux $\mathrm{XVII}^{\mathrm{e}}$ et $\mathrm{XVIII}^{\mathrm{e}}$ siècles jusqu'aux leçons inaugurales au Collège de France dans la seconde moitié $d u x^{e}$ siècle, en passant par les polémiques et leur usage, les remerciements et les mélanges. Comme le souligne l'auteur, certaines pratiques relèvent à la fois du rite et du genre : ainsi justement des mélanges, qui pour s'inscrire dans un rituel strictement codifié, n'en ont pas moins une forte identité générique. La seconde partie de l'ouvrage de Françoise Waquet, «Genres, formes et savoirs ", envisage des genres qui sont à la fois producteurs de savoir et générateurs de liens au sein de la communauté universitaire : à travers les genres comme les rites universitaires en effet, ce sont aussi les affinités entre les personnes et le fonctionnement des réseaux que l'on voit se révéler dans toute leur complexité. L'auteur constate à juste titre que les pratiques nouvelles se superposent aux genres et rites existant beaucoup plus qu'elles ne s'y substituent : ainsi le courrier électronique, qui depuis une décennie a pris une place croissante dans les échanges entre savants, n'est pas pour autant exclusif d'autres modes et d'autres formes de communication.

Le dernier chapitre, qui fait partie des contributions inédites du recueil, livre une analyse originale, celle de la session poster. Ce genre relativement nouveau, bien qu'étant désormais partie prenante de l'économie du savoir, n'avait guère été étudié jusque-là. Françoise Waquet comble cette lacune en retraçant l'histoire des posters, apparus pour la première fois à Londres en 1967 lors d'une réunion de l'English Biochemical Society ; ce n'est qu'une dizaine d'années plus tard cependant, à partir de la fin des années 1970, que la "présentation poster » s'est généralisée en tant que méthode principale de diffusion des résultats, dans le cadre de rencontres nationales et internationales. Très répandu aujourd'hui, ce nouveau genre de transmission du savoir sait aussi s'adapter aux mutations technologiques les plus pointues: récemment en effet est apparue une nouvelle forme de poster, le poster électronique, qui montre les capacités d'adaptation de la "République des lettres" aux formes nouvelles de communication du savoir.

Utilement complété par un index, l'ouvrage de Françoise Waquet constitue une contribution de premier plan à l'histoire de la construction et de la transmission du savoir universitaire, depuis le XVII e siècle jusqu'à nos jours.

\section{AUTEURS}

\section{CATHERINE VALENTI}

Université de Toulouse (UTM)

catherine.valenti@univ-tlse2.fr 